\title{
Anemia in Cardiac Surgery - Can Something Bad Get Worse?
}

Leandro Batisti de Faria ${ }^{1}$, MD; Omar Vilca Mejia ${ }^{2,3}$, MD, PhD; Leonardo Augusto Miana ${ }^{1,2}$, MD, PhD; Luiz Augusto Ferreira Lisboa², MD, PhD; Valdano Manuel2,4, MD; Marcelo B. Jatene ${ }^{1,2}$, MD, PhD; Fabio B. Jatene'2, MD, PhD; REPLICCAR Study Group

\begin{abstract}
Introduction: Anemia and blood transfusion are risk factors for morbidity/mortality in patients undergoing cardiac surgery with cardiopulmonary bypass (CPB). The objective of this study is to analyze the association of blood transfusion with morbidity/ mortality in patients undergoing coronary artery bypass grafting (CABG) under CPB in the state of São Paulo, Brazil.

Methods: This is a retrospective analysis using the State of São Paulo Registry of Cardiovascular Surgery from November 2013 to August 2014. Blood transfusion was only considered during surgery or within six hours after surgery. Anemia was defined as hematocrit $\leq 37.5 \%$. Patients < 18 years old were excluded. The sample was divided in four groups - Group I (851, no anemia), Group II (200, anemia without blood transfusion), Group III (181, no anemia and transfusion), and Group IV (258, anemia and transfusion).
\end{abstract}

Results: A total of 1,490 patients were included; 639 (42.9\%) were anemic and $439(29.5 \%)$ underwent blood transfusion. Group II showed lower composite morbidity (odds ratio [OR] -0.05; confidence interval $[\mathrm{Cl}]-0.27-0.17 ; P=0.81$ ) than Group III (OR 0.41; $\mathrm{Cl} 0.23-0.59 ; P=0.018$ ) or Group IV (OR 0.54; $\mathrm{Cl} 0.31-0.77 ; P=0.016)$. Group III was at greater risk of mortality (OR 0.73; $\mathrm{Cl}$ 0.43-1.03; $P=0.02$ ) than Group II, which was exposed only to anemia (OR -0.13; $\mathrm{Cl}-0.55-0.29 ; P=0.75)$, or Group IV (OR 0.29; $\mathrm{Cl}-0.13-0.71$; $P=0.539$ ).

Conclusion: Anemia in patients undergoing CABG with CPB is bad, but blood transfusion can be worse, increasing at least $50 \%$ the risk for mortality and/or morbidity.

Keywords: Anemia. Cardiac Surgical Procedures. Blood Transfusion. Hematocrit. Cardiopulmonary Bypass. Risk Factors.

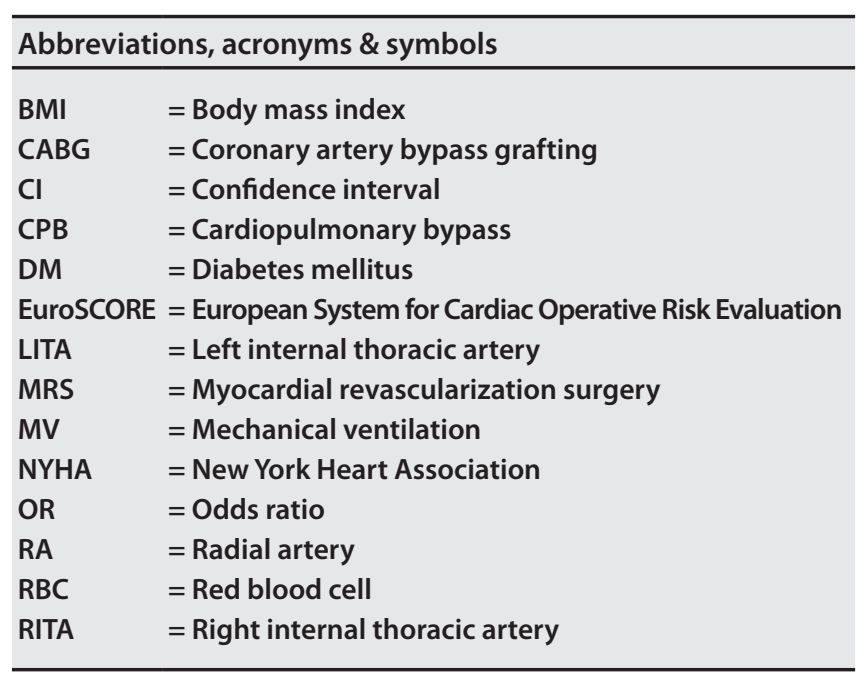

${ }^{1}$ Hospital do Coração (HCor), São Paulo, São Paulo, Brazil.

${ }^{2}$ Cardiovascular Surgery Division, Instituto do Coração do Hospital das Clínicas da Faculdade de Medicina da Universidade de São Paulo (InCor-HCFMUSP), São Paulo, São Paulo, Brazil.

${ }^{3}$ Hospital Samaritano Paulista, São Paulo, SP, Brazil.

${ }^{4}$ Cardio-Thoracic Center, Clínica Girassol, Luanda, Angola.

This study was carried out at the Cardiovascular Surgery Division, Instituto do Coração do Hospital das Clínicas da Faculdade de Medicina da Universidade de São Paulo (InCor-HCFMUSP), São Paulo, São Paulo, Brazil.

\section{INTRODUCTION}

Anemia and blood transfusion are associated with increased morbidity and mortality in heart surgery ${ }^{[1]}$. Although they do not belong to the main risk stratification score variable groups (European System for Cardiac Operative Risk Evaluation [EurOSCORE] and The Society of Thoracic Surgeons Predicted Risk of Mortality), patients who present perioperative anemia are at a higher risk of postoperative renal dysfunction and acute myocardial infarction, longer mechanical ventilation (MV) time, and mortality ${ }^{[2-4]}$.

In addition, lower hematocrit level during cardiopulmonary bypass (CPB) requires blood transfusion, thereby resulting in double risk exposure ${ }^{[5]}$. However, anemia is also associated with numerous other comorbidities and risk factors, such as advanced age, female gender, lower body surface area, ventricular dysfunction, renal failure, and heart failure; therefore, it is difficult

Correspondence Address:

Leandro Batisti de Faria

(iD) https://orcid.org/0000-0002-2930-0256

Instituto do Coração (Incor), Hospital das Clínicas, Faculdade de Medicina, Universidade de São Paulo

Av. Dr Enéias de Carvalho Aguiar, 44, Pinheiros, São Paulo, Brazil

Zip Code: 05403-000

E-mail: leandrobatisti@gmail.com 
to determine whether anemia is essentially a risk factor or is simply a marker of a more serious clinical condition ${ }^{[6,7]}$.

Our study aims to investigate the association of anemia and blood transfusion with morbidity and mortality in patients undergoing heart surgery in the state of São Paulo, Brazil, in three different perioperative management strategies: (1) no blood transfusion; (2) blood transfusion to avoid anemia; and (3) blood transfusion as a treatment of anemia.

\section{METHODS}

This is a retrospective database (State of São Paulo Registry of Cardiovascular Surgery) analysis from November 2013 to August 2014 which enrolled 1,519 patients who underwent cardiac surgery with CPB in the state of São Paulo, Brazil.

We considered only the blood transfusions (red blood cells $[\mathrm{RBC}]$ ) performed within six hours after surgery to avoid possible confounding bias related to transfusions performed after the occurrence of the morbid events. The anemia for men and women was defined as hematocrit $\leq 37.5$ (cutoff) according to the World Health Organization, or $\mathrm{WHO}^{[8]}$.

Patients aged $<18$ years and those whose preoperative hematocrit level was not available were excluded (29 patients). Of the 1,490 remaining patients included in the statistical analysis, 639 (42.9\%) patients were anemic and 439 (29.5\%) underwent intraoperative or blood transfusion within six hours after surgery.

For comparison, our cohort was divided into four groups: Group I, (851; 57.1\%) patients without anemia (hematocrit > 37.5) who did not receive blood transfusion; Group II, (200; 13.4\%) patients with anemia (hematocrit $\leq 37.5$ ), but who did not receive blood transfusion; Group III, (181; 12.1\%) patients without anemia (hematocrit $\leq 37.5$ ) who received blood transfusion; and Group IV, (258; 17.3\%) patients with anemia (hematocrit $\leq$ 37.5) who required blood transfusion; double risk exposure.

\section{Outcomes}

The database of the State of São Paulo Registry of Cardiovascular Surgery was prospectively filled according to the definitions of The Society of Thoracic Surgeons National Adult Cardiac Database. The following outcomes were analyzed at discharge and after 30 days: target-organ dysfunction (acute renal failure, acute myocardial infarction, and stroke), infection (operative wound infection, mediastinitis, endocarditis, pneumonia, and sepsis), arrhythmia (atrial fibrillation), surgical reintervention, postoperative bleeding, cardiogenic shock, and death. We considered composite outcome if any of the abovementioned complications or death took place. transfusion.

\section{Statistical Analysis}

Categorical variables were expressed as frequencies and percentages, and continuous variables were expressed as averages and standard deviations. Continuous variables with heterogeneous distribution were expressed as medians and confidence intervals $(\mathrm{Cl})$ around standard deviations. To compare preoperative and intraoperative characteristics and morbidity and mortality events between the groups, Pearson's chi-square test, Fisher's exact test, Student's t-test, and Wilcoxon's test were used, where indicated. Univariate analysis was used to determine the predictive variables of the composite outcome and in the occurrence of death. Variables found to be significantly $(P<0.10)$ related to each of the events after univariate analysis were included in the logistic regression model.

\section{RESULTS}

The baseline and intraoperative data of the four groups are summarized in Table 1. Being an older female with lower body mass index, higher EuroSCORE, and a worse functional class were the common demographic characteristics of anemic patients. They also had a more unstable clinical condition; the majority had emergency hospitalization, preoperative myocardial infarction, and a higher rate of reoperation.

Patients with lower hematocrit required more RBC units during blood transfusion (Figure 1). Of the 1,490 patients, 655 (44\%) had at least one of the studied outcomes before 30 days (Table 2).

Unadjusted analysis showed differences in postoperative complications among the groups with more negative exposures

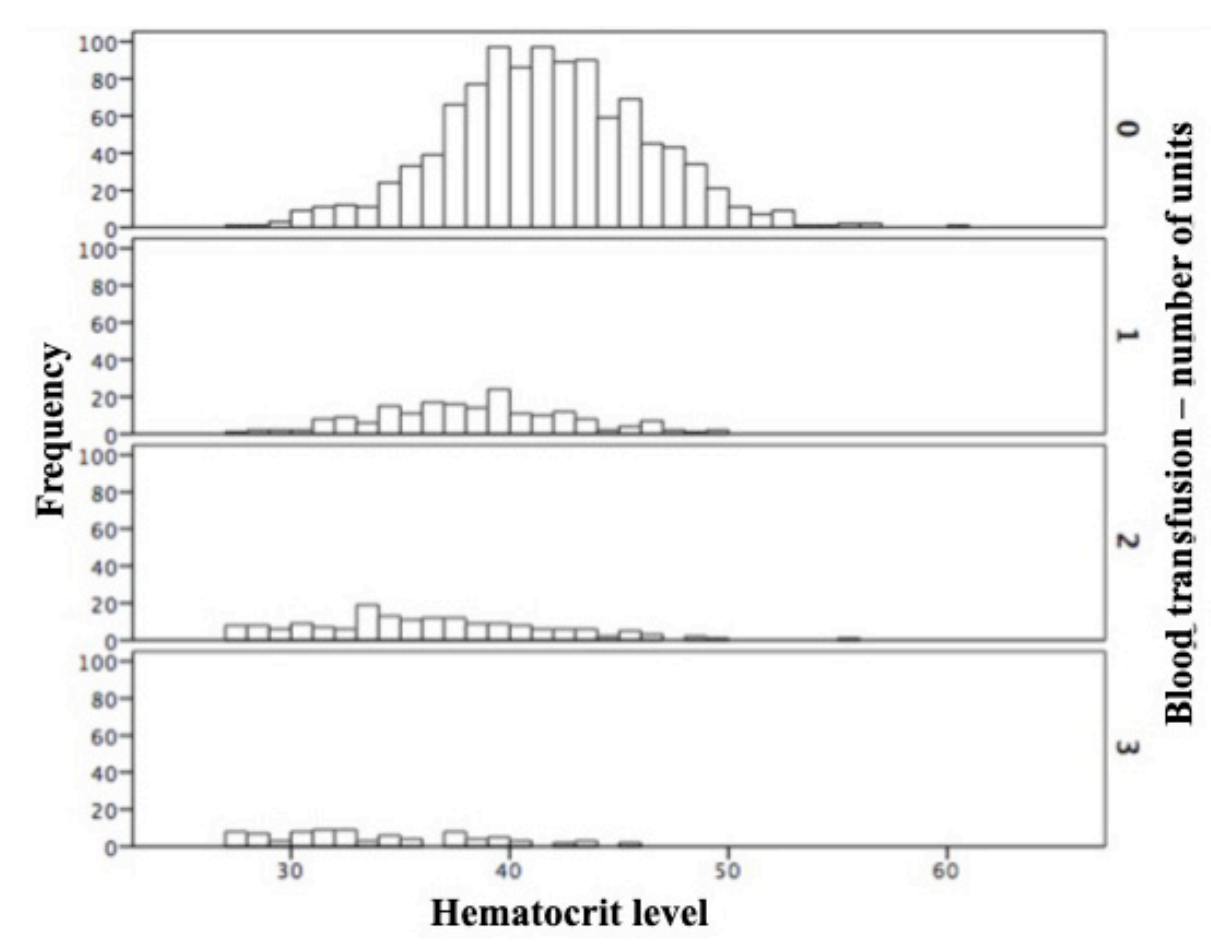

Fig. 1 - Histogram showing the relationship between preoperative hematocrit level and blood 
Table 1. Baseline characteristics of the 1,490 patients included in the analysis.

\begin{tabular}{|c|c|c|c|c|c|c|}
\hline \multicolumn{2}{|l|}{ Variables } & GI (851) & GII (200) & GIII (181) & G IV (258) & $P$-value \\
\hline \multicolumn{2}{|l|}{ Women } & $234(27.5 \%)$ & $92(46 \%)$ & $96(53 \%)$ & $125(48.4 \%)$ & $<0.001$ \\
\hline \multicolumn{2}{|l|}{ Age (years) } & $61(53-68)$ & $64(54-70)$ & $67(58-73)$ & $64(55-72)$ & $<0.001$ \\
\hline \multicolumn{2}{|l|}{ BMI } & $27(24-30)$ & $26(23-29)$ & $26(23-29)$ & $26(23-28)$ & $<0.001$ \\
\hline \multicolumn{2}{|c|}{ Insulin-dependent DM } & $90(10.6 \%)$ & $40(20 \%)$ & $26(14.4 \%)$ & $40(15.5 \%)$ & 0.002 \\
\hline \multicolumn{2}{|l|}{ Hematocrit level } & $42(40-45)$ & $36(34-37)$ & $40(39-43)$ & $33(31-35)$ & $<0.001$ \\
\hline \multicolumn{2}{|l|}{ Ejection fraction } & $60(55-65)$ & $60(53-65)$ & $60(50-66)$ & $60(50-66)$ & 0.800 \\
\hline \multicolumn{2}{|c|}{ Creatinine clearance } & $78(61-96)$ & $65(47-86)$ & $61(48-77)$ & $56(38-76)$ & $<0.001$ \\
\hline \multicolumn{2}{|l|}{ Atrial fibrillation } & $120(14.1 \%)$ & $23(11.5 \%)$ & $18(9.9 \%)$ & $39(15.1 \%)$ & 0.322 \\
\hline \multicolumn{2}{|l|}{ EuroSCORE } & $1.13(0.76-1.82)$ & $1.53(0.9-3.1)$ & $1.95(1.2-3.75)$ & $2.53(1.44-5.44)$ & $<0.001$ \\
\hline \multicolumn{2}{|l|}{ Previous infarction } & $226(26.6 \%)$ & $67(33.5 \%)$ & $68(37.6 \%)$ & $90(34.9 \%)$ & 0.003 \\
\hline \multirow{4}{*}{ NYHA } & 1 & $201(23.6 \%)$ & $37(18.5 \%)$ & $34(18.8 \%)$ & $31(12 \%)$ & \\
\hline & 2 & $325(38.2 \%)$ & $83(41.5 \%)$ & 65 (35.9\%) & $85(32.9 \%)$ & \\
\hline & 3 & $292(34.3 \%)$ & $68(34 \%)$ & $72(39.8 \%)$ & $120(46.5 \%)$ & \\
\hline & 4 & 33 (3.9\%) & $12(6 \%)$ & $10(5.5 \%)$ & $22(8.5 \%)$ & \\
\hline \multirow{5}{*}{ Previous surgery } & 0 & 774 (91\%) & $178(89 \%)$ & $155(85.6 \%)$ & $198(76.7 \%)$ & \\
\hline & 1 & $62(7.3 \%)$ & $16(8 \%)$ & $19(10.5 \%)$ & $36(14 \%)$ & \\
\hline & 2 & $13(1.5 \%)$ & $5(2.5 \%)$ & $5(2.8 \%)$ & $16(6.2 \%)$ & \\
\hline & 3 & $2(0.2 \%)$ & $1(0.5 \%)$ & $2(1.1 \%)$ & $6(2.3 \%)$ & \\
\hline & 4 & $0(0 \%)$ & $0(0 \%)$ & $0(0 \%)$ & $2(0.8 \%)$ & \\
\hline \multirow{3}{*}{$\begin{array}{l}\text { Hospitalization } \\
\text { type }\end{array}$} & Emergency & $2(0.2 \%)$ & $3(1.5 \%)$ & $2(1.1 \%)$ & $4(1.6 \%)$ & \\
\hline & Elective & 625 (73.4\%) & $136(68 \%)$ & 105 (58\%) & 137 (53.1\%) & \\
\hline & Urgency & 224 (26.3\%) & $61(30.5 \%)$ & 74 (40.9\%) & $117(45.3 \%)$ & \\
\hline \multirow{4}{*}{ MRS } & CPB & $472(55.5 \%)$ & $118(59 \%)$ & $104(57.5 \%)$ & $144(55.8 \%)$ & 0.812 \\
\hline & LITA & $511(60 \%)$ & 127 (63.5\%) & 91 (50.3\%) & $120(46.5 \%)$ & $<0.001$ \\
\hline & RITA & 76 (8.9\%) & $13(6.5 \%)$ & $2(1.1 \%)$ & $10(3.9 \%)$ & $<0.001$ \\
\hline & RA & $38(4.5 \%)$ & $7(3.5 \%)$ & $2(1.1 \%)$ & $8(3.1 \%)$ & 0.164 \\
\hline \multirow{3}{*}{ Mitral valve } & Plastic & $68(8 \%)$ & $14(7 \%)$ & $8(4.4 \%)$ & $15(5.8 \%)$ & 0.300 \\
\hline & Bioprosthesis & $96(11.3 \%)$ & $21(10.5 \%)$ & $21(11.6 \%)$ & $45(17.4 \%)$ & 0.050 \\
\hline & Mechanical prosthesis & $33(3.9 \%)$ & $8(4 \%)$ & $8(4.4 \%)$ & $18(7 \%)$ & 0.206 \\
\hline \multirow{3}{*}{ Aortic valve } & Plastic & $14(1.6 \%)$ & $1(0.5 \%)$ & $1(0.6 \%)$ & $7(2.7 \%)$ & 0.142 \\
\hline & Bioprosthesis & $127(14.9 \%)$ & $28(14 \%)$ & $45(24.9 \%)$ & $61(23.6 \%)$ & $<0.001$ \\
\hline & Mechanical prosthesis & $29(3.4 \%)$ & $9(4.5 \%)$ & $6(3.3 \%)$ & $11(4.3 \%)$ & 0.833 \\
\hline \multirow{3}{*}{ Tricuspid valve } & Plastic & $16(1.9 \%)$ & $4(2 \%)$ & $5(2.8 \%)$ & $16(6.2 \%)$ & 0.003 \\
\hline & Bioprosthesis & $3(0.4 \%)$ & $0(0 \%)$ & $1(0.6 \%)$ & $0(0 \%)$ & 0.379 \\
\hline & Mechanical prosthesis & $0(0 \%)$ & $0(0 \%)$ & $0(0 \%)$ & $1(0.4 \%)$ & 0.319 \\
\hline \multicolumn{2}{|l|}{ Aortic surgery } & $9(1.1 \%)$ & $2(1 \%)$ & $8(4.4 \%)$ & $3(1.2 \%)$ & 0.033 \\
\hline \multicolumn{2}{|l|}{ Mortality } & $37(4.3 \%)$ & $17(8.5 \%)$ & $26(14.4 \%)$ & $45(17.4 \%)$ & $<0.001$ \\
\hline \multicolumn{2}{|l|}{ Morbidity } & $325(38.2 \%)$ & $79(39.5 \%)$ & $101(55.8 \%)$ & $150(58.1 \%)$ & $<0.001$ \\
\hline
\end{tabular}

Group I: (851; 57.1\%) patients without anemia (hematocrit > 37.5) who did not receive blood transfusion; Group II: (200; 13.4\%) patients with anemia (hematocrit $\leq 37.5)$, but who did not receive blood transfusion; Group III: $(181 ; 12.1 \%)$ patients without anemia (hematocrit $\leq 37.5)$ who received blood transfusion; and Group IV: $(258 ; 17.3 \%)$ patients with anemia (hematocrit $\leq 37.5)$ who required blood transfusion; double risk exposure. $\mathrm{BMI}=$ body mass index; $\mathrm{CPB}=$ cardiopulmonary bypass; $\mathrm{DM}=$ diabetes mellitus; EuroSCORE=European System for Cardiac Operative Risk Evaluation; LITA=left internal thoracic artery; MRS=myocardial revascularization surgery; NYHA=New York Heart Association; RA=radial artery; RITA=right internal thoracic artery 
Table 2. Data on discharge and 30-day outcomes.

\begin{tabular}{|c|c|c|c|c|}
\hline Variable & No complications & $\begin{array}{c}\text { With } \\
\text { complications }\end{array}$ & $\begin{array}{l}\text { Complications up } \\
\text { to discharge }\end{array}$ & $\begin{array}{c}\text { Complications up } \\
\text { to } 30 \text { days }\end{array}$ \\
\hline Infection & $1323(88.79 \%)$ & $167(11.21 \%)$ & $51(3.42 \%)$ & $116(7.79 \%)$ \\
\hline Pneumonia & $1332(89.4 \%)$ & $158(10.6 \%)$ & $131(8.79 \%)$ & $27(1.81 \%)$ \\
\hline Acute renal failure & $1358(91.14 \%)$ & $132(8.86 \%)$ & $103(6.91 \%)$ & $9(0.6 \%)$ \\
\hline Death & $1365(91.6 \%)$ & $125(8.4 \%)$ & $116(7.8 \%)$ & $9(0.6 \%)$ \\
\hline Arrhythmia & $1380(92.6 \%)$ & $110(7.4 \%)$ & $98(6.6 \%)$ & $12(0.8 \%)$ \\
\hline Atrial fibrillation & $1387(93.1 \%)$ & $103(6.9 \%)$ & $93(6.24 \%)$ & $10(0.6 \%)$ \\
\hline Surgical reoperation & $1420(95.3 \%)$ & $70(4.7 \%)$ & $20(1.34 \%)$ & $50(3.36 \%)$ \\
\hline Low output/cardiogenic shock & $1431(96.04 \%)$ & $59(4 \%)$ & $56(3.76 \%)$ & $3(0.2 \%)$ \\
\hline Bleeding & $1441(96.7 \%)$ & $49(3.3 \%)$ & $45(3.0 \%)$ & $4(0.3 \%)$ \\
\hline Sepsis & $1442(96.8 \%)$ & $48(3.2 \%)$ & $37(2.5 \%)$ & $11(0.7 \%)$ \\
\hline Acute myocardium infraction & $1465(98.3 \%)$ & $25(1.7 \%)$ & $22(1.5 \%)$ & $3(0.2 \%)$ \\
\hline Stroke & $1468(98.5 \%)$ & $22(1.5 \%)$ & $14(0.9 \%)$ & $8(0.5 \%)$ \\
\hline Endocarditis & $1470(98.7 \%)$ & $20(1.3 \%)$ & $13(0.9 \%)$ & $7(0.5 \%)$ \\
\hline Mediastinitis & $1478(99.2 \%)$ & $12(0.8 \%)$ & $5(0.3 \%)$ & $7(0.5 \%)$ \\
\hline Systemic inflammatory response syndrome & $1481(99.4 \%)$ & $9(0.6 \%)$ & $9(0.6 \%)$ & $0(0 \%)$ \\
\hline
\end{tabular}

Table 3. Predictors of the composite outcome.

\begin{tabular}{|c|c|c|c|c|c|c|}
\hline & Estimated & Standard error & Odds ratio & \multicolumn{2}{|c|}{$95 \% \mathrm{Cl}$} & $P$-value \\
\hline Blood transfusion & 0.401 & 0.126 & 1.494 & 1.166 & 1.913 & 0.001 \\
\hline Atrial fibrillation & 0.387 & 0.163 & 1.472 & 1.069 & 2.027 & 0.018 \\
\hline Age (years) & 0.011 & 0.005 & 1.011 & 1.000 & 1.021 & 0.04 \\
\hline Creatinine clearance & -0.008 & 0.002 & 0.992 & 0.988 & 0.997 & 0.001 \\
\hline EuroSCORE & 0.0130 & 0.026 & 1.139 & 1.082 & 1.199 & 0.000 \\
\hline Constant & -0.831 & 0.447 & & & & \\
\hline
\end{tabular}

$\mathrm{Cl}=$ confidence interval; EuroSCORE=European System for Cardiac Operative Risk Evaluation

associated with worst outcomes. There was no statistically significant difference between the percentage of combined outcomes found in groups not exposed to blood transfusion $(P>0.05)$ (Figure 2). However, in the group exposed only to blood transfusion (55.8\%) and in the group with double risk exposure (58.1\%), the percentage of combined outcomes found was significantly higher $(P<0.001)$.

All variables with $P<0.10$ were included in the multiple logistic regression model. Variables in Table 3 were selected as predictors of composite outcome. A patient exposed to blood transfusion had a 1.49-fold greater chance of having a composite outcome (Table 3).
The relative effect of risk exposure to one or both risk factors on morbidity is shown in Figure 3. The Group II (no blood transfusion) (odds ratio [OR] $-0.05 ; 95 \% \mathrm{Cl}-0.27-0.17$; $P=0.81$ ) showed lower composite morbidity score than the Group III (blood transfusion) (OR 0.41; 95\% Cl 0.23-0.59; $P=0.018$ ) or Group IV (double risk exposure) (OR 0.54; 95\% Cl 0.31-0.77; $P=0.016)$.

The relative effect of risk exposure on mortality is shown in Figure 4. The Group III, exposed to blood transfusion, was at greater risk of mortality $(\mathrm{OR} 0.73 ; 95 \% \mathrm{Cl} 0.43-1.03 ; P=0.02)$ than the Group II, exposed only to anemia (OR -0.13 ; $95 \% \mathrm{Cl}-0.55-$ 0.29; $P=0.75$ ) or Group IV (OR 0.29; 95\% Cl -0.13-0.71; $P=0.539)$. 
Another important finding of this study was the influence of the amount of RBC units on morbidity. Figure 5 shows that the transfusion of three RBC units had a significant effect on morbidity (OR 1.45; 95\% Cl 1.20-1.70; $P<0.001)$.

\section{DISCUSSION}

Anemia is a serious problem in Medicine. Since modern medicine (more than 100 years ago), blood transfusion is performed for management of critically ill patients with hemorrhagic shock and sepsis ${ }^{[9,10]}$. Although transfusion was proved to save lives, it has been involved with complications and adverse events ${ }^{[1]}$.

Preoperative anemia is an independent risk factor for morbidity and mortality in patients undergoing cardiac surgery. A number of studies have demonstrated that anemia can increase the risk for mortality, five-fold higher in some of them, and also major cardiovascular and cerebrovascular events, MV time, and intensive care unit and hospital length of stay compared to non-anemic patients who underwent $\mathrm{CABG}^{[4,6,7,11]}$.

Some studies, including randomized clinical trial, with restrictive blood management have demonstrated noninferiority/superiority compared to liberal strategy regarding patients undergoing cardiac surgery ${ }^{[12-15]}$. The results of the present study were similar to that when the strategy for blood transfusion was restrictive. Liberal strategy was associated with increased risk of morbidity and mortality.

In the present study, it was observed that RBC units transfusion was associated with an increased risk of postoperative cardiac complications, such as severe infection, renal failure, neurological complications, global morbidity, and mortality, both in hospital and up to 30 days after cardiac surgery. These findings are consonant with others in the Literature $^{[1,12,16,17]}$.

This association remained strong even after adjusting for known risk factors associated with adverse outcomes. In each logistic model, RBC unit transfusion was the most reliable indicator associated with the adverse outcome, because it was chosen in $100 \%$ of the bootstrap bagging analysis.

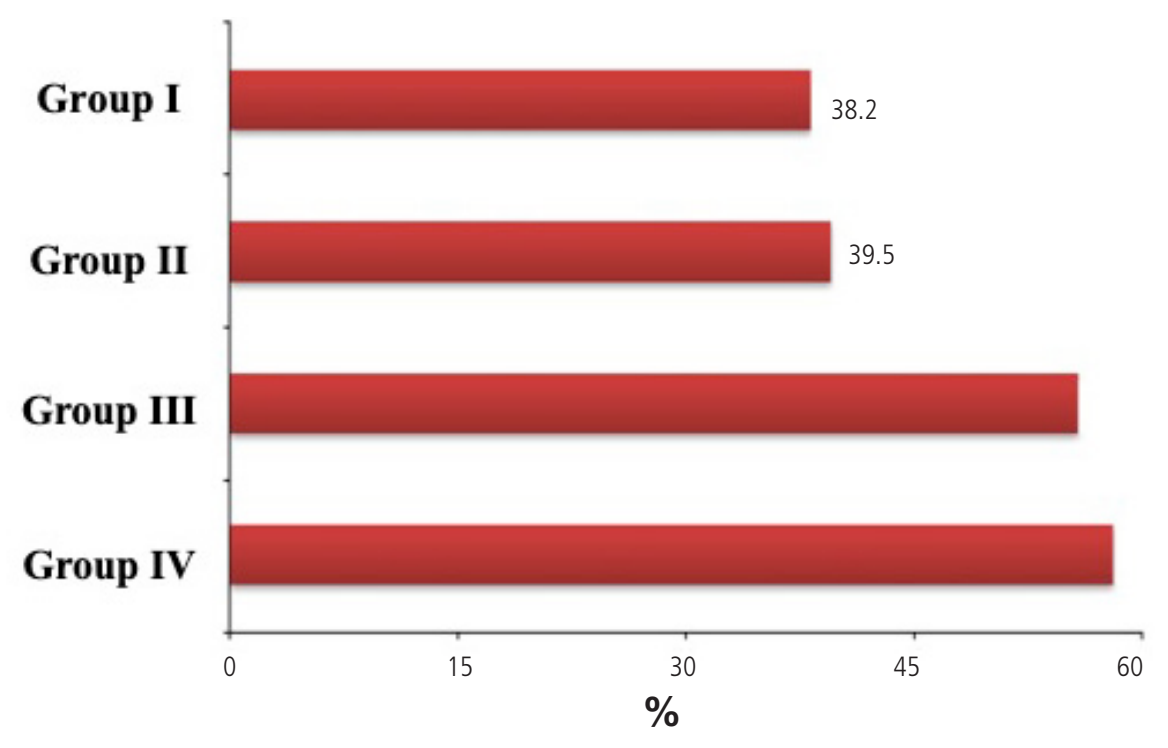

Fig. 2 - Percentage of combined outcomes in each group.

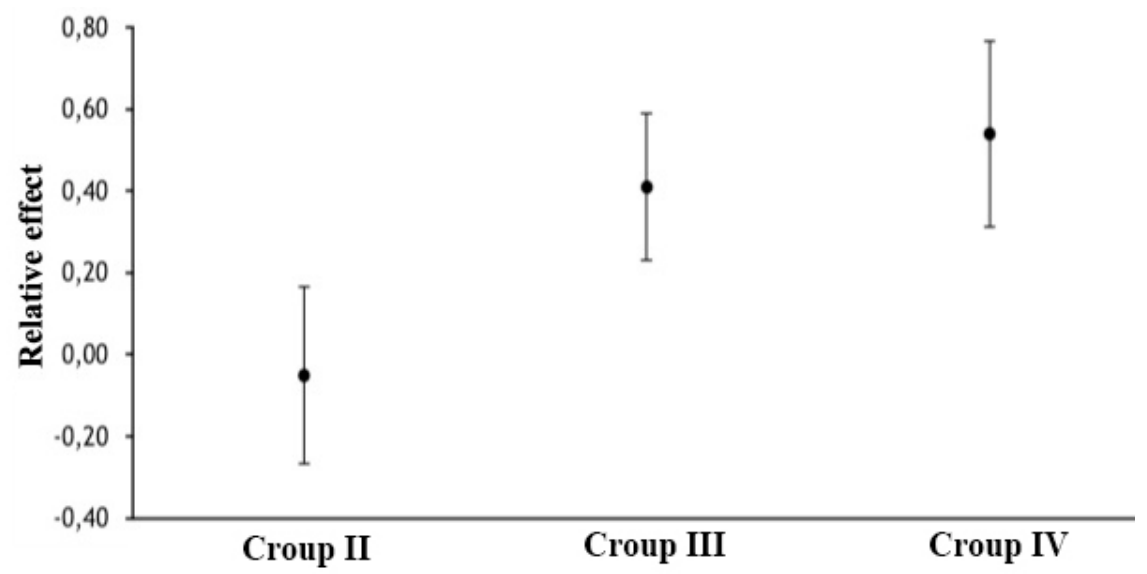

Fig. 3 - The relative effect of risk exposure on morbidity.

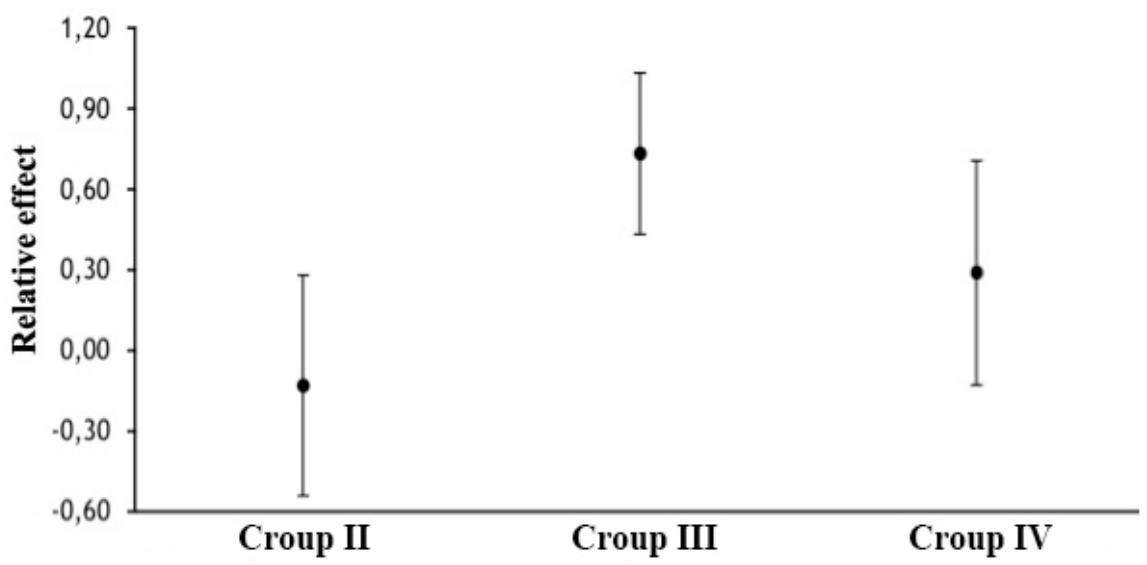

Fig. 4 - The relative effect of risk exposure on mortality. 
A large retrospective study with more than 5,000 patients showed that the RBC transfusion during or after cardiac surgery is associated with short and long-term mortality and its proportional to RBC units received. In addition, they also found association with reoperation, myocardium infarction, arrhythmia, cardiac arrest, stroke, sternal infection, pneumonia, and multi-organ failure ${ }^{[16]}$. A multicenter open-label randomized controlled trial on inferiority, which analyzed adults (5,243 patients) with moderate-to-high EuroSCORE I who underwent cardiac surgery, compared liberal and restrictive strategy and demonstrated that restrictive strategy was not inferior with respect to the composite cause of death, from any cause, myocardium infarction, stroke, renal failure requiring dialysis, and also with less RBC transfusion units ${ }^{[17]}$. It empowers the idea that a liberal RBC strategy increases the risk for morbidity and mortality even in the long-term ${ }^{[12-15]}$.

Although it is unanimous that restrictive strategy is better than liberal, in current literature, the cutoff of tolerated anemia is not well established. In one randomized controlled trial, the cutoff was $8 \mathrm{~g} / \mathrm{dL}$, but there are other cutoffs reported in the literature, such as $7.5 \mathrm{~g} / \mathrm{dL}^{[12,17]}$. There still remains doubt about how much anemia is harmful to the patient and requires transfusion.

Our findings suggest that tolerating anemia (when it is tolerable) is better than to attempt to correct it using RBC unit transfusion, because it exposes the patient to an even bigger risk. These findings are consistent with those by Loor G. et al. ${ }^{[1]}$ and Koch et al. ${ }^{[5]}$, that have shown that the intraoperative treatment for anemia, namely blood transfusions, ironically, also increases risk for morbidity and mortality ${ }^{[9]}$.

Ideally, all patients who will undergo cardiac surgery should be preoperatively clinically optimized to avoid exposure to risk factors that negatively influence outcomes. Anemia is not good, RBC transfusion is bad, but the more units of RBC the patient receives the worse. In the present study, it was well demonstrated; patients who received more RBC units had even worse outcomes. The number of RBC units was also associated with worse long-term survival in recent studies ${ }^{[15,18]}$.

The current study and the most recent evidences support that restrictive strategy is not inferior and liberal strategy is associated with worse outcomes. Therefore, perioperative management of anemia with measures to avoid blood transfusion should be initiated to mitigate transfusion needs.

\section{Limitations}

The retrospective and observational nature of this study is its main limitation. Therefore, there are variables not evaluated in this study that may be a final confounding factor of the analysis and transfusion targets and strategies varied among centers.
However, this is also a multicenter study with a significant number of patients, which confers it external validity, allowing us to generalize our findings to a different population.

\section{CONCLUSION}

RBC transfusion for patients who underwent CABG with CPB was associated with a 50\% increased risk of mortality and/ or complications. Additional transfusion was associated with an even bigger risk. In patients with anemia that did not receive transfusion, the risk was comparable to non-anemic patients that were not transfused.

\section{No financial support. \\ No conflict of interest.}

\section{Authors' roles \& responsibilities}

LBF Substantial contributions to the conception and design of the work; drafting the work; final approval of the version to be published

OVM Substantial contributions to the conception and design of the work; drafting the work; final approval of the version to be published

LAM Substantial contributions to the conception and design of the work; drafting the work; final approval of the version to be published

LAFL Revising the work; final approval of the version to be published

VM Drafting and revising the work; final approval of the version to be published

MBJ Revising the work; final approval of the version to be published

FBJ Revising the work; final approval of the version to be published 


\section{REFERENCES}

1. Loor G, Rajeswaran J, Li L, Sabik JF 3rd, Blackstone EH, McCrae KR, et al. The least of 3 evils: exposure to red blood cell transfusion, anemia, or both? J Thorac Cardiovasc Surg. 2013;146(6):1480-7.e6. doi:10.1016/j.jtcvs.2013.06.033.

2. Roques F, Nashef SA, Michel P, Gauducheau E, de Vincentiis C, Baudet $E$, et al. Risk factors and outcome in European cardiac surgery: analysis of the EuroSCORE multinational database of 19030 patients. Eur J Cardiothorac Surg. 1999;15(6):816-22; discussion 822-3. doi:10.1016/ s1010-7940(99)00106-2.

3. Edwards FH, Clark RE, Schwartz M. Coronary artery bypass grafting: the society of thoracic surgeons national database experience. Ann Thorac Surg. 1994;57(1):12-9. doi:10.1016/0003-4975(94)90358-1.

4. Loor G, Li L, Sabik JF 3rd, Rajeswaran J, Blackstone EH, Koch CG. Nadir hematocrit during cardiopulmonary bypass: end-organ dysfunction and mortality. JThorac Cardiovasc Surg. 2012;144(3):654-62.e4. doi:10.1016/j. jtcvs.2012.03.058.

5. Koch CG, Li L, Duncan Al, Mihaljevic T, Cosgrove DM, Loop FD, et al. Morbidity and mortality risk associated with red blood cell and bloodcomponent transfusion in isolated coronary artery bypass grafting. Crit Care Med. 2006;34(6):1608-16. doi:10.1097/01.CCM.0000217920.48559.D8.

6. Zindrou D, Taylor KM, Bagger JP. Preoperative haemoglobin concentration and mortality rate after coronary artery bypass surgery. Lancet. 2002;359(9319):1747-8. doi:10.1016/S0140-6736(02)08614-2.

7. Kulier A, Levin J, Moser R, Rumpold-Seitlinger G, Tudor IC, SnyderRamos SA, et al. Impact of preoperative anemia on outcome in patients undergoing coronary artery bypass graft surgery. Circulation. 2007;116(5):471-9. doi:10.1161/CIRCULATIONAHA.106.653501.

8. World Health Organization. Iron deficiency anemia: assessment, prevention and control. A guide for programme managers. WHO/ NDH/01.3. Geneve: WHO/NHD; 2001.

9. Vincent JL, Baron JF, Reinhart K, Gattinoni L, Thijs L, Webb A, et al. Anemia and blood transfusion in critically ill patients. JAMA. 2002;288(12):1499507. doi:10.1001/jama.288.12.1499.

10. Mitra B, Mori A, Cameron PA, Fitzgerald M, Paul E, Street A. Fresh frozen plasma (FFP) use during massive blood transfusion in trauma resuscitation. Injury. 2010;41(1):35-9. doi:10.1016/j.injury.2009.09.029.
11. Karkouti K, Wijeysundera DN, Beattie WS; Reducing Bleeding in Cardiac Surgery (RBC) Investigators. Risk associated with preoperative anemia in cardiac surgery: a multicenter cohort study. Circulation. 2008;117(4):47884. doi:10.1161/CIRCULATIONAHA.107.718353.

12. Hajjar LA, Vincent JL, Galas FR, Nakamura RE, Silva CM, Santos MH, et al. Transfusion requirements after cardiac surgery: the TRACS randomized controlled trial. JAMA. 2010;304(14):1559-67. doi:10.1001/ jama.2010.1446.

13. Koch C, Li L, Figueroa P, Mihaljevic T, Svensson L, Blackstone EH. Transfusion and pulmonary morbidity after cardiac surgery. Ann Thorac Surg. 2009;88(5):1410-8. doi:10.1016/j.athoracsur.2009.07.020.

14. Surgenor SD, DeFoe GR, Fillinger MP, Likosky DS, Groom RC, Clark $C$, et al. Intraoperative red blood cell transfusion during coronary artery bypass graft surgery increases the risk of postoperative lowoutput heart failure. Circulation. 2006;114(1 Suppl):I43-8. doi:10.1161/ CIRCULATIONAHA.105.001271.

15. Chelemer SB, Prato BS, Cox PM Jr, O'Connor GT, Morton JR. Association of bacterial infection and red blood cell transfusion after coronary artery bypass surgery. Ann Thorac Surg. 2002;73(1):138-42. doi:10.1016/ s0003-4975(01)03308-2.

16. Bhaskar B, Dulhunty J, Mullany DV, Fraser JF. Impact of blood product transfusion on short and long-term survival after cardiac surgery: more evidence. Ann Thorac Surg. 2012;94(2):460-7. doi:10.1016/j. athoracsur.2012.04.005.

17. Mazer CD, Whitlock RP, Fergusson DA, Hall J, Belley-Cote E, Connolly $\mathrm{K}$, et al. Restrictive or liberal red-cell transfusion for cardiac surgery. N Engl J Med. 2017;377(22):2133-44. doi:10.1056/NEJMoa1711818.

18. Koch CG, Li L, Duncan Al, Mihaljevic T, Loop FD, Starr NJ, et al. Transfusion in coronary artery bypass grafting is associated with reduced longterm survival. Ann Thorac Surg. 2006;81(5):1650-7. doi:10.1016/j. athoracsur.2005.12.037.

19. van Straten AH, Hamad MA, van Zundert AJ, Martens EJ, Schönberger JP, de Wolf AM. Preoperative hemoglobin level as a predictor of survival after coronary artery bypass grafting: a comparison with the matched general population. Circulation. 2009;120(2):118-25. doi:10.1161/ CIRCULATIONAHA.109.854216. 